\title{
Health Communication and Psychological Distress: Exploring the Language of Self-harm
}

\author{
Kevin Harvey and Brian Brown
}

\begin{abstract}
This study explores adolescents' accounts of self-harm with a view to elucidate the implications for health care practitioners seeking to administer care to teenagers in English. Drawing on a corpus of 1.6 million words from messages posted on a UK-hosted adolescent health Web site, analysis began by identifying a range of keywords relating to self-harm. The subsequent contextual examination of these keywords afforded a close description of the contributors' experiences of self-harm and the factors that resulted in their selfinjurious behaviours. A recurring theme was that of the habitual nature of self-harm, with the act being represented as a form of addiction over which they had little control. Self-harmers construct the phenomenon as particularly powerful, and the act is formulated as the only effective means of relief from emotional turmoil. If we are to increase parents and health professionals' ability to respond to self-injury in the medium of English, close linguistic attention to individuals' accounts of self-harm is valuable. Online health resources are also valuable means of eliciting concerns from distressed adolescents who are often reluctant to seek support from professionals face-to-face.
\end{abstract}

Keywords: adolescents, corpus linguistics, Internet and electronic health communication, self-harm

Résumé : L'étude porte sur des récits d'automutilation faits par des adolescents et cherche à en tirer des conséquences pour les intervenants en santé des adolescents offrant des soins en langue anglaise. À partir d'un corpus de 1,6 million de mots tirés de messages affichés sur un site Web britannique spécialisé en santé adolescente, l'analyse a consisté dans un premier temps à dresser une liste de mots clés associés à l'automutilation. L'examen contextuel subséquent de ces mots clés a permis de décrire précisément les expériences vécues par les jeunes auteurs des messages, de même que les facteurs à la source de leurs comportements autodestructeurs. L'un des thèmes récurrents des descriptions est le caractère habituel de l'automutilation, et la représentation du geste comme une forme de dépendance difficile à dominer. Pour les automutilateurs, le phénomène est un construit particulièrement puissant, et ils perçoivent le geste comme étant le seul soulagement efficace à leurs bouleversements émotionnels. Si l'on veut augmenter la capacité de réaction par le langage des parents et des professionnels de la santé anglophones devant l'automutilation, l'attention linguistique qu'on accorde aux récits d'automutilation peut 
s'avérer très utile. Les ressources en santé disponibles en ligne sont également des moyens utiles de rassurer les adolescents désemparés et inquiets, une clientèle souvent réfractaire à l'aide professionnelle directe.

Mots clés : adolescents, analyse linguistique, Internet et communication électronique en santé, automutilation

This article is concerned with the problem of self-harm in adolescents and offers some insights into how health professionals, mental health workers, and carers from a variety of language communities can gain some understanding of how this troubling and increasing problem is expressed and experienced by sufferers. We will explore online communication as a way of making sense of this phenomenon and examine its potential as a means of informing health care practitioners seeking to provide services to teenagers in the medium of English about the nature of the problem, the concepts and vocabularies used, and the idioms of distress deployed by the age group for whom selfinjury is an increasing but often hard-to-disclose phenomenon.

We will show how our focus on the language of self-harm can elucidate patterns and commonalities in adolescents' accounts of the psychological distress accompanying self-injury, giving voice to an age group whose subjective experiences of health and illness are acknowledged to be difficult to reach by health professionals. Self-harm is believed to be increasing within the context of a rise in psychological problems among youth in many nations (Moreno, et al., 2007), but little is known about the language that adolescents use to articulate emotional turmoil to others. One of the obvious difficulties of researching self-harm is that it is a stigmatized and highly sensitive subject. Furthermore, the language that surrounds self-injurious behaviour constitutes a private, specialist discourse of which health professionals non-native speakers of English in particular - are unlikely to be aware. We aim to demonstrate the utility and relevance of interrogating the linguistic routines of adolescents, arguing that it is important for practitioners to pay close attention to such patterns of language if they are to appreciate 'the richness of everyday communication about health care issues' (Brown, Crawford, \& Carter, 2006, p. 139).

\section{Adolescent mental health and self-harm}

A major concern for adolescent mental health is the rate of self-harm among teenagers. In the United Kingdom, the problem is particularly acute: rates of self-harm are reported to be higher in the UK than in the rest of Europe, with, for example, one in five adolescents believed 
to have engaged in self-harming behaviour (Mental Health Foundation, 2006). Concerns are being raised internationally, with researchers in Scandinavia (Franzén \& Gottzén, 2011), Europe and Australasia (Madge et al., 2008), and the United States (Briere \& Gil, 1998; Lang \& Sharma-Patel, 2011) identifying significant minorities of adolescents expressing their distress in this way. Furthermore, research into adolescent self-harm has shown that official figures are only likely to represent the 'tip of the iceberg' (Ystgaard et al., 2009) since self-harm rates among adolescents who do not receive assistance from health care services are significantly higher than rates obtained from hospital records (Bowen \& John, 2001; Hawton, Rodham, Evans, \& Weatherall, 2002). Indeed, it is estimated that only $10 \%$ of adolescents who harm themselves will present at a hospital after a self-harming episode (Hawton et al., 2002).

However, despite being a common clinical problem, self-harm is an under-researched subject (Mental Health Foundation, 2006). It is not surprising, therefore, that it is poorly understood by and provokes ambiguous feelings in health professionals (Skegg, 2005) who have expressed concerns in appropriately responding to the needs of individuals who self-harm (Hadfield, Brown, Pembroke, \& Hayward, 2009). As Hurry, Aggleton, and Warwick (2000) observe, the domain of youth mental health is largely defined by adults, with youth's emotional problems being commonly assessed through an adult respondent (pp. 6-8). The perspectives of teenagers in relation to their psychological distress might be obscured or overlooked altogether. Although the literature in the area of self-harm continues to grow apace, there remains comparatively little communication-based research that explores the linguistic repertoires - the communicative patterns and commonalities - through which adolescents represent their subjective experiences of and views on self-injurious behaviour (Coggan, Patterson, \& Fill, 1997). It has not generally been in the purview of existing research to give detailed attention to the personal perspectives and situated communicative routines of adolescents who self-harm, denying them the opportunity of 'speaking for themselves' (Nicolson, 1995, p. 339). In this sense, much of the research ignores the concepts and images within cultures from which individuals make sense of their experiences' (McQueen \& Henwood, 2002, p. 1494) and the meanings teenagers attach to self-harm in the context of their everyday lives.

Accordingly, the present study responds to calls for increasing research that explores the personal perspectives of emotionally distressed adolescents (Hetherington \& Stoppard, 2002) and examines the implications for those seeking to offer services to this group 
through the medium of English. If we are to increase our understanding of why some adolescents choose to injure themselves and increase the capacity of health professionals and carers from a variety of language communities to respond to intentional self-injury (Abrams \& Gordon, 2003), it is important to gather and interpret adolescents' reported experiences of and motivations for self-harming behaviour. Detailed attention to individuals' subjective experiences of self-harm and the discursive means through which such problems are communicated is important since, as Manley and Leichner (2003) argue, effective treatment of psychological disturbance involves, in no small part, recognizing and validating the considerable despair that adolescents may be personally experiencing (p. 33). A common complaint among individuals who self-harm is that other people's failing to understand their self-injurious behaviour invalidates their experiences (Adams, Rodham, \& Gavin, 2005).

\section{Health care language learning and corpus linguistics}

The teaching of second languages to health care practitioners wishing to practice in languages other than their native tongues has recently been enlivened by the inclusion of methods from data-driven learning. Here, data sets of health care communication in the target language are studied for insights into how complaints are formulated and expressed and how intervention may be phrased and targeted so as to yield maximum benefit to the patient. This trend toward the study of the practice of health care communication was outlined originally by Thomas and Wilson (1996) in the case of doctor-patient interaction, followed by Crawford, Johnson, Brown, and Nolan (1999) in the case of mental health nursing, and Adolphs, Brown, Carter, Crawford, and Sahota (2004) in a study of the UK's National Health Service (NHS) Direct consultations. Wiggins (2009) adopted the approach to the study of conversation about weight management, Watermeyer and Penn (2009) have applied it in exploring interactions between pharmacists and clients, and Da Silva and Dennick (2010) have examined problem-based learning discussions. Skelton and his colleagues have examined face-to-face activities in medicine using several techniques familiar to the corpus linguist, such as the role of concordancing in analyzing general practice consultations (Skelton and Hobbs, 1999), metaphorical expressions used in general practice consultations (Skelton, Wearn, \& Hobbs, 2002a), and the use of pronouns in consultations (Skelton, Wearn, \& Hobbs, 2002b). What is clear from much of this exploration is that talk with clients includes many non-standard colloquial forms and idioms which can be hard to anticipate and understand using textbook knowledge. These represent 
an additional challenge to the language learner seeking to administer health care through the medium of English, over and above mastering the technical vocabulary of health care (Crawford \& Brown, 2010).

In addition, it is important that practitioners in all languages grasp the implications of self-injury for their practice as many people who seek help from health professionals after having self-harmed report negative experiences (McHale \& Felton, 2010). Moreover, online environments are important fora in which self-injury can be discussed (Franzén \& Gottzén, 2011; Whitlock, Powers, \& Eckenrode, 2006) as it is often not readily disclosed in face-to-face situations as a result of the social taboos that accompany it (Shaw, 2002). Therefore, there is considerable value in exploring Web-based presentations of self-harm, both for the information they contain about this hitherto relatively obscure expression of distress and the instruction it can provide to those seeking to administer health care that is sensitive to the needs of those who self-harm in the sufferers' own language.

\section{Methodology}

To illustrate how a corpus approach to health communication can identify and describe patterns in commonalities in the discourse of psychological distress, we will interrogate a corpus of electronic messages submitted by adolescents to a Web site dedicated to teenage health, the Teenage Health Freak (http://www.teenagehealthfreak. org). Operated by UK-based doctors specializing in adolescent health, the Teenage Health Freak is an English language Web site that has been running since its launch in 2000. The forum is a popular online health resource for adolescents, receiving an average of 52,864 visits per day. The Web site is designed to be interactive, confidential, and evidence-based, providing adolescents with accessible advice and information pertaining to a broad range of health issues. Although this study does not make precise demographic claims about the nature of the users who access the Web site, it is likely to be accessed by a wide range of individuals predominantly from anglophone countries.

A key feature of the Web site allows teenagers to E-mail health questions in confidence to the online general practitioner (GP), Doctor Ann. Given the large influx of messages that the site receives on a daily basis, it is not possible for the Web site's doctors to respond to all of the requests for help. Consequently, only a small number of messages are answered by the Dr. Ann medical team. However, all contributors are automatically directed to the appropriate parts of the Web site where they can receive advice and information about their specific health concerns. Unlike data from other interactive health Web sites, which, in sections such as Frequently Asked Questions, reformulate 
and standardize messages sent by users seeking health advice, the data used in this study reproduce the entire, unedited queries and concerns posted to the site doctors. Consequently, this allows for access to the original word choice and syntactical construction of the E-mail requests, retaining any grammatical or orthographical inconsistencies and all of the nuances of individual expression in the adolescents' discourse.

Permission was granted by the Teenage Health Freak operators to collect and analyze the messages sent to the Web site. Comprising 1.6 million words, a selection covering the period from 2004 to 2008, the data used in this study provide a substantial snapshot of contemporary health concerns communicated on a regular basis by the teenage contributors. The Teenage Health Freak Web site has a privacy policy in place informing contributors that their requests might be used for research purposes and that, in using the Web site to transmit such information, they consent to the collection and use of the data they provide.

\section{Results}

As a way into this substantial data set and to provide a survey of the salient health themes in the corpus, the first stage of the analysis involved identifying keywords that appeared in the corpus of health messages. To this end, we generated a list of keywords that provide a thematic characterization of the health E-mail corpus. Keywords, according to McCarthy and Handford (2004), are words that 'best define' (p. 174) a text or texts - that is, words that are significantly higher in one language variety than in another. Keywords are an important indicator of both expression and content (Seale, Boden, Williams, Lowe, \& Steinberg, 2007) and have been used by an increasing number of researchers as a reliable means of identifying key themes in characterizing health language corpora (Adolphs et al., 2004; Harvey, Brown, Crawford, Macfarlane, \& McPherson, 2007; Seale, 2006; Seale et al., 2007). In this sense, a 'keyword' is one which is statistically more frequent, rather than the usual sense of words deemed to be of significant social and cultural importance. The advantage of using statistical keywords is that they eliminate the analyst's a priori biases from the identification of themes of significance and interest (Baker 2004; Seale, Ziebland, \& Charteris-Black, 2006). Thus, keywords present the analyst with evidence that a conventional thematic qualitative analysis might obscure from view (Seale, 2006), serving as an effective means of identifying salient themes that warrant further exploration in context (Baker, 2006). 
We used WordSmith Tools (Scott, 2004) to compare the corpus of adolescent health E-mails from the Teenage Health Freak Web site with a collection of one million words of general spoken English from the British National Corpus. Spoken language is an appropriate language variety with which to compare the E-mails since, although the messages are written, they are in an informal language variety and are dialogic. Thus, speech is a more appropriate point of comparison than the more literary or technical styles commonly found in written language (Harvey et al., 2008). The comparison identified 1,160 keywords pertaining to a range of health-related themes in the adolescent health messages (Table 1).

The keywords in Table 1 direct us to lexical elements in the corpus of health-related communications from which it is possible to identify meaningful clusters of content items indicative of health concerns and issues. Although informed by clearly defined semantic areas, the categories overlap to some extent. For instance, HIV and AIDS could also fall under the rubric Serious Conditions, and antidepressants and Prozac could fall under Medication. Moreover, issues concerning body image are intimately connected with mental health, with, for instance, bodily appearance occasionally being cited by adolescents as a reason for selfharm and suicidal impulses. Nevertheless, the keyword categorizations in Table 1 describe the central health themes that most commonly

Table 1: Keywords by categorization of health themes in adolescent health E-mails

\begin{tabular}{|c|c|}
\hline Theme & Examples of keywords \\
\hline Sexual health & $\begin{array}{l}\text { sex, HIV, AIDS, STD, STI, sperm, contraception, clitoris, vagina, } \\
\text { pregnant, period, orgasm, vulva, PMS, erection, condom, masturbate, } \\
\text { gay, abortion, foreplay, intercourse, virgin, unprotected, lesbian, oral, } \\
\text { pill, ovulation, herpes, thrush, chlamydia, pregnancy, tampon, testicles, } \\
\text { genitalia, Viagra, scrotum, labia, glans, ovaries, foreskin, balls, fanny, } \\
\text { bisexual, miscarriage }\end{array}$ \\
\hline Mental health & $\begin{array}{l}\text { antidepressants, cut, depressed, cuts, cutting, self-harm, scars, } \\
\text { Prozac, angry, sad, depression, self, harm, wrists, suicide, die, } \\
\text { overdose, addiction, addict, stress, stressed, ADHD, paranoid, mental, } \\
\text { mad, moods, sad, unhappy, crying, personality, anxiety }\end{array}$ \\
\hline Body weight/image & $\begin{array}{l}\text { Eat, eating, anorexia, anorexic, weight, size, overweight, fat, obese, } \\
\text { underweight, skinny, thin, bulimia, BMI, exercise, diets, kilograms, KG, } \\
\text { KGS, bulimia, calories }\end{array}$ \\
\hline Drugs/alcohol & $\begin{array}{l}\text { Drugs, cannabis, cocaine, heroin, pills, alcohol, drunk, drinking, } \\
\text { poppers, mushrooms, marijuana, crack, ecstasy, addict, stoned, LSD, } \\
\text { cigarettes, dope }\end{array}$ \\
\hline Serious conditions & cancer, HIV, AIDS, epilepsy, diabetes, anthrax \\
\hline Minor conditions & $\begin{array}{l}\text { pimples, spots, acne, zits, blackhead, mumps, scabies, dandruff, } \\
\text { worms, cystitis }\end{array}$ \\
\hline Medication & $\begin{array}{l}\text { medicine, antidepressants, Prozac, medication, prescribed, antibiotics, } \\
\text { tablets, pill, pills }\end{array}$ \\
\hline
\end{tabular}


Table 2: Most common self-harm-related keywords in adolescent health messages

\begin{tabular}{rlr}
\hline & \multicolumn{1}{c}{ Word } & Frequency \\
\hline 1 & cut & 314 \\
2 & self-harm & 175 \\
3 & cutting & 122 \\
4 & self-harming & 61 \\
5 & cuts & 55 \\
6 & slit & 18 \\
7 & harm & 16 \\
8 & harming & 12 \\
9 & self-harmer & 10 \\
10 & slitting & 7 \\
\hline
\end{tabular}

concern adolescents, along with the various key lexical elements that constitute these themes.

Prominent among these mental-health-themed keywords are terms relating to self-harm and psychological distress broadly (Table 2). The rich constellation of keywords pertaining to emotional concerns provides a valuable linguistic resource for exploring the adolescent perspective, not least the identification and description of patterns and commonalities in the way the Web site users experience and conceptualize their experiences and understandings of psychological distress. However, since examining keywords in isolation contributes little to a situational understanding of language use, the next stage of the corpus interrogation involved a more qualitative approach to the data that is, the examination of particular salient linguistic terms in contextual detail, specifically the collocates that surround and are commonly associated with these salient expressions of self-harm. Collocation is a linguistic phenomenon whereby two words commonly appear together - the tendency of one word, as Hunston (2002) puts it, to attract another. Collocation can be reliably measured computationally using a statistical measure. We used WordSmith Tools (Scott, 2004) to calculate the Mutual Information (MI) scores of the collocates that were commonly associated with the key terms related to self-harm in the adolescent health messages. Derived from information theory, MI is a measure of the strength of collocation when compared with chance, calculating the extent to which words appear together (Skelton et al., 2002a). The MI score indicates the strength of the collocation (i.e., the firmness of the link between co-occurring words). Conventions in corpus linguistics take an MI rating of $>3$ as significant - that is, as indicative of a strong collocation (Hunston, 2002; Skelton et al.). Accordingly, we only recorded collocates that were either equal to or above this value of significance. 
Table 3: Most common collocates of cut and self-harm

\begin{tabular}{llcc}
\hline & Collocate & Frequency & Mutual information \\
\hline 1 & help & 81 & 9.60 \\
2 & stop & 60 & 6.79 \\
3 & friend & 46 & 5.55 \\
4 & started & 45 & 9.83 \\
5 & feel & 28 & 7.78 \\
6 & depressed & 19 & 12.40 \\
7 & years & 16 & 10.39 \\
8 & blood & 12 & 10.05 \\
\hline
\end{tabular}

In short, collocational analysis afforded a systematic overview of the themes and issues surrounding a given keyword, enabling the discovery and description of patterns and commonalities in the adolescents' accounts of self-harming behaviour. Table 3 lists the most frequent lexical collocates of the words cut and self-harm, which were the most common underlying expressions used by the contributors to refer to self-harm. Having identified the collocates, the final stage of the analysis involved a qualitative analysis of the self-harm messages to appreciate more subtle and detailed uses of meaning and recurring patterns of communication across the texts. Analysis afforded close description of the adolescents' attitudes toward and understanding of self-harm, yielding valuable insights into the reasons why they hurt themselves and the problems they encounter responding to their emotional distress.

In examining the collocates in Table 3, several central themes and issues surrounding the subject of self-harm emerge. For instance, the act is associated with notions of time, duration, and cycles (started, stop, years); low mood or depression (feel, depressed); support and assistance (help); and peers (friends). Although the majority of the messages contributed to the Teenage Health Freak are self-featuring - that is, the problems described therein relate to the contributors themselves the reoccurrence of the collocate friend suggests that several messages ostensibly relate to the predicaments of peers, with contributors writing on behalf of close associates, although these third-person-focused messages might potentially be substitutes for self-featuring problems, forms of 'disguised presentations' (Holmes, Offen, \& Waller, 1997, p. 80). The adolescents' messages that present the self-harming behaviours of friends are a useful point of entry as they contain themes that occur right across the entire spectrum of self-harming concerns. Interestingly, as the examples in Box 1 illustrate, messages concerning friends are characteristically short, consisting of no more than three or four clauses. 
Box 1: Messages concerning friends

- my friend is self harming how can i help her

- one of my mates cuts his arms every time something bad happens to him how can i make him stop cutting hisself?

- what can i do to make my fraind stop self harming

- what shall $i$ tell my frient to stop her cutting her arms purposely?

- my friend has been self-harming herself lately what should $i$ do or say to her?

- what happens if your friend is doing drugs and cutting there selfs because of there life problems, what do you do?

- hey my friend has depression and she is self-harming her self what should $\mathrm{i}$ do?

- my friend self harms she wont stop what should $i$ tell her?

Although brief, these messages nevertheless provide a clear sense of some of the problems experienced by individuals who reported as engaging in self-harming behaviour. Self-harm is recognized as a problem which correspondents want to 'help' their friends 'stop,' a behaviour that is associated with depression and triggered by negative life events (although these are not elaborated here). Even though self-harm is constructed as problematic behaviour in which they deem it appropriate to intervene or at least broach, the contributors in no way impart a sense of blame on their friends or censure them for their activities. Critical judgment is completely withheld. There is, for instance, no indication that friends are being manipulative or are seeking attention, reactions which, according to some researchers, are very common to self-harm (Clark, 2002; Mental Health Foundation, 2006), even from people who would normally be regarded as close sources of support, such as family and friends (Strong, 1998).

As the above examples attest, stopping and receiving help for selfinjurious behaviour emerge as recurring concerns. However, these brief accounts tell us only a limited amount about adolescents' experiences of self-harm and certainly nothing about what it means to them. To obtain a fuller picture, let us consider a random selection of messages that contain the most common collocates help and stop presented in Box 2.

Although these messages repeat some of the concerns described in the friend-related messages, they provide more detailed accounts of personal experiences of self-harm, with several persistent new themes emerging. For example, self-harm is presented as a response to physical and sexual abuse, verbal bullying, and family turmoil as well as a reaction to feeling upset and depressed. Self-harm is constructed as a survival mechanism, a form of relief, or as one of the contributors puts it, a means of trying 'to deal with it,' in this instance 'it' being the trauma of sexual abuse. Self-harm also appears to serve as a visual manifestation of distress, although the actual physical injuries that 
Box 2: Random selection of messages that contain the common collocates help and stop

- i tried to stop self harming, and i managed 5 weeks 3 days, and i failed after that, and i know ive let myself down but alot has happened to me, which made me self harm in the first place, i kept things inside me for soo long, and i have suport from skool which is gr8 help, like i have my mentor and another teacher, but recently ive started to keep it inside me and is making me self harm, and $\mathrm{i}$ always wrote to my teacher to say how $\mathrm{i}$ felt, but something stops me now, and the alternatives i used instead of self harming dont help nomore. what can i do. i know i need help, but i cant stay strong with the self harming, so much hurt is inside me and i cant get it out of my head. . please please relpy!!

- i need 2 cut myself all the time. help me pls

- i have recently started cutting myself and i want to stop but i cant . ive treid loads of things and im woried becase when ever i get upset i start to visualise myslef cutting . and then when im alone if $i$ havent calmed down i start cutting and $i$ want to stop. $i$ hate having to hide my cuts/scars and i need help

- i smoke but im not addicted it just makes me better as i get easily stressed. have you got any suggestions for things i could do instead because i started smoking to stop myself from cutting myself

- Doctor Ann: About a year ago I stopd cutting myself with a penknife because l'd managed to sort out my life. The other day my family had a row and I started to cut myself using kitchen knives, straight across my wrists. One of my friends saw the scars today, and everyone thinks l'm doing it for attention, but them thinking that partially lead to it anyway - it's a catch 22 situation Help!

- i got sexually abused when i was 5 till 11 and i cant get over it i've had coucnelling but it doesnt help now i just cut myself all the time to try and deal with it

- i get called names because i wear glasses and have ginger hair the name calling got so bad i have started to cut my wrists please help

- i keep going depressed. i get so upset now i start to heave, im on anti depressants but only been on them a week. i spent a year in hopsital to help with my self-harming (cutting) issues nothing has changed it has got worse and so has my ocd. just want to be happy and not so panicky and insecure

- CAN YOU HELP ME WITH SELF HARMING OR NOT ITS BEEN GOING ON KNOW FOR 3 YEARS AND I JUST CARNT STOP WHAT SHOULLD I DO CAN YOU HELP ME THANK YOU

- I've started slitting my wrists, it's my way of coping with my problems. But now I really want to stop the scars are really ugly!! But i duno how 2 i feel i need to cut or I'll break!!! Please Help!!!

- i self harm and i whant some help i hate my self for ding it it is like a vitiose circle is there any thing $u$ can do that would help me to stop i do not whant to talk to my parents

speak for those who cut (Ross, 1994, p. 13) can also be a source of disquiet: 'I really want to stop the scars are really ugly!!'; 'i hate having to hide my cuts/scars.' These accounts thus reveal some of the intolerable circumstances in which adolecents self-harm. Although the act is portrayed as a survival mechanism or a response (regardless of how maladaptive to unbearable emotional distress [Favazza, 1996]), its legacy of cuts and scars, which have to be treated and hidden from others, only appears to aggravate the predicaments of Web site users who experience self-harm as an effective form of relief. As one 
correspondent succinctly sums up the situation, 'it's a catch 22 situation Help!'

Interestingly, self-harm is also perceived to be an alternative to other risky behaviours. In an effort to avoid it, adolescents participate in other deleterious activities, such as smoking. Yet, such is the pull of cutting that these substitutes are comparatively less compelling and so abandoned in favour of self-harming behaviours. One of the adolescents comments, 'the alternatives i used instead of self harming dont help nomore.' The pull of self-harm over and above these other risk behaviours can perhaps be further explained by the broad range of motives presented by adolescents for the activity. As an antidote to psychological upheaval, self-harm is hard to replace since it can occur for several reasons, while at the same time fulfilling different functions (Horne \& Csipke, 2009, p. 656), be it emotional release or articulating (i.e., visualizing) inexpressible distress.

However, as this last observation helps demonstrate, the theme that most strongly comes through in these messages is the compulsive and habitual quality of self-harm. For instance, self-harm is part of a repetitive cycle ('i just cut myself all the time') that is liable to escalate, becoming ever more acute: ' $I$ 'm worried that one day it [cutting] might get too much'; 'it has got worse.' Self-harm is referred to as a 'vitiose circle' and is described in terms of enduring desire: ' $\mathrm{i}$ need 2 cut all the time.' Its persistent and cyclic nature is further emphasized by the length of time for which the behaviour has been occurring and the amount of time during which the adolescents have been able to refrain from harming themselves: 'ITS BEEN GOING ON FOR 3 YEARS'; 'I have been cutting and burning myself for about two or three years'; 'i managed 5 weeks and 3 days, and i failed after that.'

The foregoing discussion raises the question of whether self-harm is, for those who participate in it, an addiction along with other risk behaviours, such as drug and alcohol dependency. The question of whether self-harm is actually addictive is a controversial and contested one (Strong, 1998; Sutton, 2005). Babiker and Arnold (1997), for example, argue that to formulate self-harm as an addiction with all the negative associations that doing so involves 'is to pathologize the process unnecessarily' (p. 134). Yet, the adolescents whose messages are analyzed in this study do appear to construct addict identities for themselves, drawing consistently on the language of addiction: ' $i$ tried to stop'; 'i can't stop'; 'i want to stop but i cant'; 'is there anything u can do that would help me to stop'; and so forth. In the sense that necessity replaces pleasure and dependency replaces choice (Sutton), the adolescents construe their self-harm as addiction or, at the very least, a behaviour that possesses a strong addictive quality. 
Box 3: Selection of messages featuring the dependency terms addiction, addicted, and habit

- I know cutting yourself is a problem for me its an addiction, but what none of my friends understand is im not doing it for suicide reasons. I dont want to kill myself . . . i really dont. I cut because i dont know how to deal with my pain so $i$ take it out on my self or ill be really mad so ill just cut. Ive cut my wrists alot thats mostly where and my legs abit but i really dont know what to do about my friends or how to stop, i mean to me its not a bad thing $i$ have the power i like that i could kill myself but iam not trying to so to me its not a problem how doi tell other people it feels good and stuff with out them thinking im crazy

- I've got a really bad habit because evrytime my mum and I or me and my little sister have an arguement I take the scissors out from under my bed and I start slitting my wrists - I don't know what to do because after every fight I feel so depressed and the only way I feel I can get rid of this

- hey $\mathrm{i}$ have had a problem of cutting myself and $\mathrm{i}$ am worried that $\mathrm{i}$ am addicted to it cause whatever i do i cant stop its really anoying cause evrytime i am depressed i cut myself wat can i do?

- I have depression, and am on medication and receiving CBT. over the past few months i have developed the habit of pulling out the top part of my pubic hair, covering part of my mons area. It looks horrible, and I always want to pull out any growing hairs. but i'm realising it is a problem because im getting obsessed with it and have even cut the skin to get to trapped hairs. i need some advice. Please help, $i$ think this is a form of abuse depression is to harm myself - please give me some advice - I'm really upset and I don't want my mum to find them - it will break her heart

- Self Injury has always been a problem for me. It started that i NEEDED to do it. It made alot of the \#! @\%!! better for along time. I found out one of my best mates had been cutting since she was a kid - and we dediced to give up together . . . It was hard, but I gave up for 10 months before having a set back. I now dont need to do it . . . But $\mathrm{i}$ like it. Its a habbit. I Like the whole blood thing, feeling the cuts as they heal and looking after them. ... It sounds werid but what can i do about it?! Some things trigger me off - like My boss at work. Some College teachers . . Stress and of course arguments - but as I'm not into seein a therapist . . . is there anything else i can do!?

- i self harm and it really helps me in a way i have an addiction to it! i cant stop but it feels good when i do it

The theme of addiction is not alone confined to these examples. In the context of self-harm, the following dependency terms also occur: addiction, addicted, and habit (Box 3).

Again, as with the previous set of examples, these messages illustrate - often graphically and in unflinching, exposing detail - that once one begins on a course of self-harm, it becomes extremely difficult to stop. Although the addictive and habitual nature of self-harm is clearly constructed as a problem and therefore something that needs to be checked, it is also portrayed - albeit on one occasion - in contrary terms: cutting is 'not a problem' since it produces positive, even pleasant, effects ('it feels good and stuff'), while investing the self-harming adolescent with a substantial degree of 'power' ('i have the power $i$ like that i could kill myself but iam not trying to'). In this instance (the 
first message in Box 3), addiction to self-harm is not a 'bad thing.' It is only a problem in the eyes of other people: cutting is a legitimate activity, an acceptable form of relief from intolerable pain and anger, and thus, despite the rational, scientific logic that construes it as nonunderstandable, possesses an 'internal logic' (Harris, 2000, p. 169). The concern at the heart of the problem is responding to the negative perceptions and judgments of others, not the actual behaviour of selfharm itself. In other words, how does one reconcile self-harm, which society considers to be a disturbing and senseless act, with a nonpathological identity? As the contributor puts it, 'how do i tell other people it feels good and stuff with out them thinking im crazy.'

The addictive quality of self-harm has consequences for the sufferers' representations of personal agency and control over their actions. Broadly speaking, addiction - be it to self-harm, gambling, alcohol, or illicit drugs - is commonly conceived as a constraint on self-motivated actions (Bailey, 2005). Thus, as an addiction, self-harm is represented as a behaviour over which the individual has little, if any, personal control. Self-harm is construed as a behaviour which cannot be personally overcome and to which there are no apparent alternatives: 'whatever i do i can't stop its really annoying'; 'the only way I feel I can get rid of this depression is to harm myself'; 'is there anything else i can do!?' The perceived inability to generate personal solutions to problems here is indicative of a state of hopelessness, whether expressly stated ('my life is worthless, it's not worth living!') or otherwise implied. Hopelessness is considered to be a significant factor influencing self-harming behaviours (Anderson, Woodward, \& Armstrong, 2004), and as the above examples attest, the adolescents appear to have reached such states of despair that the only way out is by recourse to 'maladaptive problem-solving techniques,' such as cutting (McLaughlin, Miller, \& Warwick, 1996, p. 524).

There is a telling irony at work here. Participating in self-harm is widely acknowledged as a means of being in control of one's life and feelings (Babiker \& Arnold, 1997; Boynton \& Auerbach, 2004; Plante, 2007; Strong, 1998). If individuals are powerless to act against the often-appalling life events that have affected and continue to affect them, events that include sexual and physical abuse, family trauma, and bullying as well as the experience of crippling mood disorders such as depression, they are at least still able to exert a degree of control over their own bodies. As the previously mentioned E-mails have illustrated, self-harm functions as a method of coping with internal rage, grief, or pain, relieving adolescents of oppressive feelings. No matter how destructive their acts of self-harm might appear to them (and to other people), in taking part in such behaviours they are at 
least able to convert their chaos into calm, their powerlessness into control (Favazza, 1996).

Yet although self-harm undeniably provides a sense of control, the adolescents ironically have very little control over their self-mutilation - this unique form of personal agency. Thus, they appear to be in a double bind, having little control over the only behaviour which, paradoxically, affords them some degree of empowerment over their life situations. Plante $(2007$, p. 56$)$ argues that the power to cut or not to cut rests entirely with those who self-harm. However, as the foregoing analysis has broadly demonstrated, the Web site users consistently articulate a contrary view: self-harm is an activity from which it is impossible, or at least very difficult, to escape. Rather than being a symbol of autonomy and power, as it is commonly described in the mental health literature, self-harm is, at least for these adolescents, more symbolic of the absence of control - something which exerts a considerable influence over them.

\section{Discussion}

This study has identified some of the recurring linguistic routines through which adolescents articulate their personal accounts of psychological distress online. The research was designed to provide a discourse-based perspective to enrich our understanding of the private and highly stigmatized phenomenon of self-harm. Analysis of the health E-mail corpus revealed several significant patterns and commonalities in adolescents' accounts of self-harm, insights that further consolidate our understanding of self-injurious activity, which continues to remain under-researched (Mental Health Foundation, 2006). Consequently, this study addresses what is still missing from our conception of teenage turmoil: the voice of adolescents' themselves (Jacobson et al., 2002). Our research, we hope, can help equip health care providers to intervene most effectively in this enigmatic and disturbing area.

The findings of this study, therefore, demonstrate how specialized corpus data can be analyzed using computer-aided techniques to address real-world problems. Empirical, corpus-based medical-discourse studies have a place in the education of health care practitioners from a variety of language communities, with corpus approaches to the analysis of health language data affording novel ways of raising professionals' consciousness and advancing their knowledge and practice of health communication (Crawford \& Brown, 2010, p. 1). With regard to adolescent mental health and the issue of self-harm, if professionals are to tailor support that reflects the uniqueness of adolescents' experiences within a particular language community, it is important 
for them to be aware of adolescents' accounts of psychological distress. The way people formulate their accounts, deploy vocabularies and concepts, and create meaning in their particular native language will be an invaluable resource for practitioners seeking to intervene effectively to treat emotional health problems.

While the findings in this article reflect the concerns of anglophone youth, the value for the language learner of people's accounts of their difficulties in their own words should be underscored. Corpora such as the one under study in the present article may disclose idioms of distress distinctive to particular ethnolinguistic communities (de Jong \& Reis, 2010) and enable scrutiny of the 'more subtle cultural forms that channel and structure the ways and the means by which people express their distress' (Massé, 2000, p. 413).

For an issue like self-harm, which has relatively recently attracted the sustained attention of the clinical and scholarly communities, this article underscores the notion that any interventions focusing entirely on correcting behaviour in adolescents who self-harm may be incomplete or misdirected (Adams et al., 2005). Scrutiny of the various meanings that the Web site users personally attach to self-harm suggests that health providers from both the same and differing language communities need to have flexible and linguistically nuanced responses to adolescents who injure themselves, being aware that there are often multiple and complex situational reasons for the activity and that it cannot simply be reduced to a problem inherent in the individual (Johnstone, 1997). As in Franzén and Gottzén's (2011) Web-based research, several of the adolescents in this study construed self-harm not as a problem for themselves but rather as a problem in the eyes of others. As McAllister (2003) argues, unless multiple meanings are identified and considered among professionals, it is likely that conventional and ill-fitting beliefs will be maintained and unsatisfactory outcomes will persist.

Although self-harm appeared to afford adolescents a degree of relief from their problems, the persistence of emotional turmoil meant that the acts of self-injurious behaviour provided only temporary respite for the contributors, and therefore the practice had to be repeated for it to sustain its effects. The repetitive nature of self-harm described so vividly by the Web site users here reflects its habitual and compulsive nature. An example of a distinctive idiom identified in the present study was the notion that self-harm was akin to an addiction and was thus represented as an activity which they were unable to cease. In portraying self-harm as an overpowering addiction, many of the writers minimized the role of their personal agency and stressed their inability to control their self-harming activity. In 
this sense, their discourses of addiction can be seen as translating behaviour that is 'bad' and 'purposive' into behaviour that is 'non-volitional' (Davies, 1998, p. 270). A corollary of portraying their behaviour in this way is that the contributors present themselves as not culpable for their actions: one, so the logic dictates, cannot be reasonably blamed for something over which one has no personal influence.

These subjective accounts of self-harm as addiction raise some important questions about the language of self-harm and, with it, the values and beliefs that health professionals, and society more generally, have about self-harm and individuals who injure themselves. In much of the medical literature, particularly in North America, the term self-harm is often prefaced by the qualifier deliberate or intentional to denote bodily harm without suicidal intent (Skegg, 2005). Yet, as Allen (2007) argues, prefixing the term in this way pejoratively 'reinforces the notion that the person could refrain from doing this if he or she tried' (p. 174). However, of interest to both the native English speaker and the second language learner is the way in which sufferers in this study present it as not simply a matter of wanting and deciding to stop and then willfully desisting from self-injury. These contributors communicated the sense that, with self-harm as a mode of essential release, necessity had replaced pleasure and dependency had replaced choice. Consequently, they felt that they had little control or choice over what they did.

The accounts examined in this study reveal the adeptness with which adolescents use electronic communication to disclose their health concerns. The research supports previous studies that describe how individuals are more likely to express emotional turmoil online than they are voice-to-voice. A characteristic linguistic feature of the Teenage Health Freak messages was their striking candour. Despite the extremely face-threatening act of personally disclosing and admitting to psychological distress (Pollock, 2007), the adolescents spoke candidly and without apparent inhibition, describing their predicaments and behaviours in explicit, personal detail and typically eschewing euphemism in favour of more direct and intimate expression. Thus, the research highlights the importance of electronic forms of advice-seeking that might be taken up by distressed teenagers who might be hard to reach through better known channels of support (Armson, 1997).

Given the regularity with which electronic forms of communication are enthusiastically adopted by adolescents - with more than $90 \%$ of North American youth regularly using the Internet (Burns, Durkin, \& Nicholas, 2009) - there is considerable scope for more extensive and systematic use of interactive Web-based health care. Computer- 
mediated communication constitutes a practical resource for eliciting emotionally rich disclosures from vulnerable teenagers who might have no other means of obtaining emotional support. The availability of such channels of communication plays an important part in reducing adolescents' need to engage in self-harming behaviour (Manley \& Leichner, 2003), allowing them to discuss difficult feelings which otherwise might remain undisclosed. Web-based fora thus provide unique and candid insights for practitioners, youth workers, and carers seeking to explore the formulations of problems and the concepts and vocabularies deployed so as to undertake more sensitive assessments and interventions with this group.

\section{Conclusion and directions for future research}

In conclusion, let us highlight the role and value of the Web-based health forum as a means of eliciting highly sensitive concerns from a generation that has often been reluctant to consult practitioners, peers, and others for personal health advice and information face-toface (Suzuki \& Calzo, 2004). The corpus approach to health communication affords an effective means of identifying the incremental effect' (Baker, 2006, p. 13) of patterns across large quantities of text, allowing the researcher and the language learner to discover linguistic routines which are liable to remain submerged in extensive data sets. The subtle, yet powerful, presence and full implication of these commonalities and patterns in the linguistic routines of adolescents might well be overlooked by health professionals and policy-makers unaccustomed to considering the significance of language in determining their responses to self-harm. If responses are to be successful, close attention to the discursive routines of individuals who self-harm must not be taken for granted, as this study has sought to demonstrate. Language must not be regarded simply as a medium for education and intervention (Cameron \& Kulick, 2003, p. 154), but discussed expressly as part of any response to the problem. Using data sets such as we have presented here in education for health professionals might well yield important and unexpected opportunities for advancing health care communication, both for second language learners of English in health care work, where a data-driven approach is gaining momentum, and in terms of a wider applicability in health communication learning as a whole. It would be a valuable innovation if the learning of English as a second language via data-driven learning were to contribute to a more critical and evidence-based approach to health language practices among practitioners with English as a first language as well. 
In this article we have begun to highlight the value of analyzing naturally occurring online health discourse as a means of understanding adolescents' emotional concerns and gaining insight for practitioners concerned with this phenomenon. There is, however, scope to take this and related health communication research further, particularly in the area of second language learning where the use of online health corpora can potentially improve second language input for health professionals, helping them develop what we might call 'health communicative competence' when interpreting and responding to medical issues (Crawford \& Brown, 2010). Moreover, online environments are growing as significant fora in which people seek health information and disclose problems (Fox \& Jones, 2009; Kummervold et al., 2008) and within which health care professionals of many linguistic backgrounds are keen to develop competence. Future work could focus on the use of speech acts and pragmatic features in online health disclosures to help second language learners identify the typical discourse norms and structures that occur in the electronic mode of health-problem formulation in comparison with other modes of medical interaction (such as in face-to-face professional-patient consultations and written case records). The discourse and pragmatic structure of online health-problem construction is liable to differ from verbal clinical encounters, with, for instance, the opening (greeting) and closing (sign off) of electronic health messages showing greater unpredictability and informality than verbal doctor-patient consultations (Mullany \& Harvey, 2007) and exhibiting elevated levels of directness and candour (Suler, 2004). Communicative competence in the context of health care involves not only close familiarization with recurring task-specific lexical items but also appreciating that the medical setting continuously involves mediating between various modes of communication (Tannen \& Wallat, 1986, p. 296).

Correspondence should be addressed to Kevin Harvey, University of Nottingham, Room A100 Trent, University Park, Nottingham, NG7 2RD, UK. E-mail: kevin.harvey@nottingham.ac.uk.

\section{References}

Abrams, L., \& Gordon, A. (2003). Self-harm narratives of urban and suburban young women. Affilia, 18, 429-444.

Adams, J., Rodham, K., \& Gavin, J. (2005). Investigating the 'self' in deliberate selfharm. Qualitative Health Research, 15(10), 1293-1309. http://dx.doi.org/ 10.1177/1049732305281761. Medline:16263913

Adolphs, S., Brown, B., Carter, R., Crawford, P., \& Sahota, O. (2004). Applying corpus linguistics in a health care context. Journal of Applied Linguistics, 1(1), 9-28. http://dx.doi.org/10.1558/japl.1.1.9.55871 
Allen, S. (2007). Self-harm and the words that bind: A critique of common perspectives. Journal of Psychiatric and Mental Health Nursing, 14, 172-178.

Anderson, M., Woodward, L., \& Armstrong, M. (2004). Self-harm in young people: A perspective for mental health nursing care. International Nursing Review, 51(4), 222-228. http://dx.doi.org/10.1111/j.1466-7657.2004.00234.x. Medline:15530162

Armson, S. (1997). Suicide and cyberspace - befriending by e-mail. Crisis, 18(3), 103-105. http://dx.doi.org/10.1027/0227-5910.18.3.103

Babiker, G., \& Arnold, L. (1997). The language of injury: Comprehending selfmutilation. Oxford: Blackwell.

Bailey, L. (2005). Control and desire: The issue of identity in popular discourses of addiction. Addiction Research and Theory, 13(6), 535-543. http://dx.doi.org/ $10.1080 / 16066350500338195$

Baker, P. (2004). Querying keywords: Questions of difference, frequency, and sense in keywords analysis. Journal of English Linguistics, 32(4), 346-359. http://dx.doi.org/10.1177/0075424204269894

Baker, P. (2006). Using corpora in discourse analysis. London: Continuum.

Bowen, A., \& John, A. (2001). Gender differences in presentation and conceptualization of adolescent self-injurious behaviour: Implications for therapeutic practice. Counselling Psychology Quarterly, 14(4), 357-379. http:// dx.doi.org/10.1080/09515070110100956

Boynton, P., \& Auerbach, A. (2004). 'I cut because it helps': Narrative of self-injury in teenage girls. In B. Hurwitz, T. Greenhalgh, \& V. Skultans (Eds.), Narrative research in health and illness (pp. 95-114). London: BMJ Books. http://dx.doi. org/10.1002/9780470755167.ch6

Briere, J., \& Gil, E. (1998). Self-mutilation in clinical and general population samples: Prevalence, correlates, and functions. The American Journal of Orthopsychiatry, 68(4), 609-620. http://dx.doi.org/10.1037/h0080369. Medline:9809120

Brown, B., Crawford, P., \& Carter, R. (2006). Evidence-based health communication. Maidenhead, UK: Open University Press.

Burns, J.M., Durkin, L.A., \& Nicholas, J. (2009). Mental health of young people in the United States: What role can the Internet play in reducing stigma and promoting help seeking? The Journal of Adolescent Health, 45(1), 95-97. http://dx.doi.org/10.1016/j.jadohealth.2008.12.006. Medline:19541256

Cameron, D., \& Kulick, D. (2003). Language and sexuality. Cambridge: Cambridge University Press. http://dx.doi.org/10.1017/CBO9780511791178

Clark, A. (2002). Language of self harm is somatic and needs to be learnt. British Medical Journal, 324(7340), 788-789. http://dx.doi.org/10.1136/ bmj.324.7340.788/a. Medline:11923168

Coggan, C., Patterson, P., \& Fill, J. (1997). Suicide: Qualitative data from focus group interviews with youth. Social Science and Medicine, 45(10), 1563-1570. http://dx.doi.org/10.1016/S0277-9536(97)00098-1. Medline:9351146 
Crawford, P., \& Brown, B. (2010). Health communication: Corpus linguistics, data driven learning and education for health professionals. Taiwan International ESP Journal, 1, 1-26.

Crawford, P., Johnson, A.J., Brown, B.J., \& Nolan, P. (1999). The language of mental health nursing reports: Firing paper bullets? Journal of Advanced Nursing, 29(2), 331-340. http://dx.doi.org/10.1046/j.1365-2648.1999.00893.x. Medline:10197932

Da Silva, A.L., \& Dennick, R. (2010). Corpus analysis of problem-based learning transcripts: An exploratory study. Medical Education, 44(3), 280-288. http://dx. doi.org/10.1111/j.1365-2923.2009.03575.x. Medline:20444059

Davies, J.B. (1998). Pharmacology versus social process: Competing or complementary views on the nature of addiction? Pharmacology and Therapeutics, 80(3), 265-275. http://dx.doi.org/10.1016/S0163-7258(98)00031-X. Medline:9888697

de Jong, J.T., \& Reis, R. (2010). Kiyang-yang, a West-African postwar idiom of distress. Culture, Medicine and Psychiatry, 34(2), 301-321. http://dx.doi.org/ 10.1007/s11013-010-9178-7. Medline:20422270

Favazza, A. (1996). Bodies under siege: Self-mutilation and body modification in culture. Baltimore: John Hopkins University Press.

Fox, S., \& Jones, S. (2009). The social life of health information. Washington, DC: Pew Internet.

Franzén, A.G., \& Gottzén, L. (2011). The beauty of blood? Self-injury and ambivalence in an Internet community. Journal of Youth Studies, 14(3), 279-294. http://dx.doi.org/10.1080/13676261.2010.533755

Hadfield, J., Brown, D., Pembroke, L., \& Hayward, M. (2009). Analysis of accident and emergency doctors' responses to treating people who self-harm.

Qualitative Health Research, 19(6), 755-765. http://dx.doi.org/10.1177/ 1049732309334473. Medline:19429768

Harris, J. (2000). Self-harm: Cutting the bad out of me. Qualitative Health Research, 10(2), 164-173. http://dx.doi.org/10.1177/104973200129118345.

Medline:10788281

Harvey, K., Brown, B., Crawford, P., Macfarlane, A., \& McPherson, A. (2007). 'Am I normal?' Teenagers, sexual health and the Internet. Social Science and Medicine, 65(4), 771-781. http://dx.doi.org/10.1016/j.socscimed.2007.04.005. Medline:17499898

Harvey, K., Churchill, D., Crawford, P., Brown, B., Mullany, L., Macfarlane, A., \& McPherson, A. (2008). Health communication and adolescents: What do their emails tell us? Family Practice, 25(4), 304-311. http://dx.doi.org/10.1093/ fampra/cmn029

Hawton, K., Rodham, K., Evans, E., \& Weatherall, R. (2002). Deliberate self harm in adolescents: Self report survey in schools in England. British Medical Journal, 325(7374), 1207-1211. http://dx.doi.org/10.1136/bmj.325.7374.1207.

Medline:12446536

Hetherington, J.A., \& Stoppard, J.M. (2002). The theme of disconnection in adolescent girls' understanding of depression. Journal of Adolescence, 25(6), 619-629. http://dx.doi.org/10.1006/jado.2002.0509. Medline:12490180 
Horne, O., \& Csipke, E. (2009). From feeling too little and too much, to feeling more and less? A nonparadoxical theory of the functions of self-harm. Qualitative Health Research, 19(5), 655-667. http://dx.doi.org/10.1177/ 1049732309334249. Medline:19380501

Holmes, G.R., Offen, L., \& Waller, G. (1997). See no evil, hear no evil, speak no evil: Why do relatively few male victims of childhood sexual abuse receive help for abuse-related issues in adulthood? Clinical Psychology Review, 17(1), 69-88. http://dx.doi.org/10.1016/S0272-7358(96)00047-5. Medline:9125368

Hunston, S. (2002). Corpora in applied linguistics. Cambridge: Cambridge University Press.

Hurry, J., Aggleton, P., \& Warwick, I. (2000). Introduction. In P. Aggleton, J. Hurry, \& I. Warwick (Eds.), Young people and mental health (pp. 1-10). Chichester, UK: Wiley.

Jacobson, L., Churchill, R., Donovan, C., Garralda, E., Fay, J., \& Adolescent Working Party, RCGP. (2002). Tackling teenage turmoil: Primary care recognition and management of mental ill health during adolescence. Family Practice, 19(4), 401-409. http://dx.doi.org/10.1093/fampra/19.4.401. Medline:12110563

Johnstone, L. (1997). Self-injury and the psychiatric response. Feminism and Psychology, 7(3), 421-426. http://dx.doi.org/10.1177/0959353597073025

Kummervold, P.E., Chronaki, C.E., Lausen, B., Prokosch, H.-U., Rasmussen, J., Santana, S., Staniszewski, A., \& Wangberg, S.C. (2008). eHealth trends in Europe 2005-2007: A population-based survey. Journal of Medical Internet Research, 10(4), e42. http://dx.doi.org/10.2196/jmir.1023. Medline:19017584

Lang, C.M., \& Sharma-Patel, K. (2011). The relation between childhood maltreatment and self-injury: A review of the literature on conceptualization and intervention. Trauma, Violence and Abuse, 12(1), 23-37. http://dx.doi.org/ 10.1177/1524838010386975. Medline:21288933

Madge, N., Hewitt, A., Hawton, K., de Wilde, E.J., Corcoran, P., Fekete, S., van Heeringen, K., De Leo, D., \& Ystgaard, M. (2008). Deliberate self-harm within an international community sample of young people: Comparative findings from the Child \& Adolescent Self-harm in Europe (CASE) Study. Journal of Child Psychology and Psychiatry, and Allied Disciplines, 49(6), 667-677. http://dx. doi.org/10.1111/j.1469-7610.2008.01879.x. Medline:18341543

Manley, R.S., \& Leichner, P. (2003). Anguish and despair in adolescents with eating disorders-helping to manage suicidal ideation and impulses. Crisis, 24(1), 32-36. http://dx.doi.org/10.1027/ /0227-5910.24.1.32. Medline:12809151

Massé, R. (2000). Qualitative and quantitative analyses of psychological distress: Methodological complementarity and ontological incommensurability. Qualitative Health Research, 10(3), 411-423. http://dx.doi.org/10.1177/ 104973200129118426. Medline:10947485 
McAllister, M. (2003). Multiple meanings of self harm: A critical review. International Journal of Mental Health Nursing, 12(3), 177-185. http://dx.doi. org/10.1046/j.1440-0979.2003.00287.x. Medline:17393644

McCarthy, M., \& Handford, M. (2004). 'Invisible to us': A preliminary corpusbased study of spoken business English. In U. Connor \& T. Upton (Eds.), Discourse in the professions: Perspectives from corpus linguistics (pp. 167-201). Amsterdam: John Benjamins.

McHale, J., \& Felton, A. (2010). Self-harm: What's the problem? A literature review of the factors affecting attitudes towards self-harm. Journal of Psychiatric and Mental Health Nursing, 17(8), 732-740. http://dx.doi.org/10.1111/j.13652850.2010.01600.x. Medline:21050340

McLaughlin, J., Miller, P., \& Warwick, H. (1996). Deliberate self-harm in adolescents: Hopelessness, depression, problems and problem-solving. Journal of Adolescence, 19(6), 523-532. http://dx.doi.org/10.1006/jado.1996.0051. Medline: 9245304

McQueen, C., \& Henwood, K. (2002). Young men in 'crisis': Attending to the language of teenage boys' distress. Social Science and Medicine, 55(9), 1493-1509. http://dx.doi.org/10.1016/S0277-9536(01)00186-1. Medline:12297237

Mental Health Foundation. (2006). Truth hurts - Report of the national inquiry into self-harm among young people. London: Mental Health Foundation.

Moreno, C., Laje, G., Blanco, C., Jiang, H., Schmidt, A.B., \& Olfson, M. (2007). National trends in the outpatient diagnosis and treatment of bipolar disorder in youth. Archives of General Psychiatry, 64(9), 1032-1039. http://dx.doi.org/ 10.1001/archpsyc.64.9.1032. Medline:17768268

Mullany, L., \& Harvey, K. (2007 July 2-4). Fluid boundaries of politeness in adolescentdoctor CMC encounters. Paper presented at Third International Symposium on Politeness, University of Leeds, Leeds, UK.

Nicolson, P. (1995). Qualitative research, psychology and mental health: Analysing subjectivity. Journal of Mental Health (Abingdon, England), 4(4), 337-346. http:// dx.doi.org/10.1080/09638239550037398

Pollock, K. (2007). Maintaining face in the presentation of depression: Constraining the therapeutic potential of the consultation. Health, 11(2), 163-180. http://dx. doi.org/10.1177/1363459307074692. Medline:17344270

Plante, L. (2007). Bleeding to ease the pain: Cutting, self-injury and the adolescent search for self. Connecticut: Praeger.

Ross, M. (1994). Maggy Ross. In L. Pembroke (Ed.), Self-harm: Perspectives from personal experience (pp. 14-16). London: Survivors Speak Out.

Scott, M. (2004). WordSmith tool help manual. Version 4.0. Oxford: Oxford University Press.

Seale, C. (2006). Gender accommodation in online cancer support groups. Health, 10(3), 345-360. http://dx.doi.org/10.1177/1363459306064495.

Medline:16775019

Seale, C., Boden, S., Williams, S., Lowe, P., \& Steinberg, D. (2007). Media constructions of sleep and sleep disorders: A study of UK national 
newspapers. Social Science and Medicine, 65(3), 418-430. http://dx.doi.org/ 10.1016/j.socscimed.2007.03.035. Medline:17466425

Seale, C., Ziebland, S., \& Charteris-Black, J. (2006). Gender, cancer experience and Internet use: A comparative keyword analysis of interviews and online cancer support groups. Social Science and Medicine, 62(10), 2577-2590. http://dx.doi. org/10.1016/j.socscimed.2005.11.016. Medline:16361029

Shaw, S.N. (2002). Shifting conversations on girls' and women's self-injury: An analysis of the clinical literature in historical context. Feminism and Psychology, 12(2), 191-219. http://dx.doi.org/10.1177/0959353502012002010

Skegg, K. (2005). Self-harm. Lancet, 366(9495), 1471-1483. http://dx.doi.org/ 10.1016/S0140-6736(05)67600-3. Medline:16243093

Skelton, J.R., \& Hobbs, F.D. (1999). Concordancing: Use of language-based research in medical communication. Lancet, 353(9147), 108-111. http://dx.doi. org/10.1016/S0140-6736(98)02469-6. Medline:10023896

Skelton, J.R., Wearn, A.M., \& Hobbs, F.D. (2002a). A concordance-based study of metaphoric expressions used by general practitioners and patients in consultation. British Journal of General Practice, 52(475), 114-118.

Medline: 11887876

Skelton, J.R., Wearn, A.M., \& Hobbs, F.D. (2002b). 'I' and 'we': A concordancing analysis of how doctors and patients use first person pronouns in primary care consultations. Family Practice, 19(5), 484-488. http://dx.doi.org/10.1093/ fampra/19.5.484. Medline:12356699

Strong, M. (1998). A bright red scream: Self-mutilation and the language of pain. London: Virago.

Suler, J. (2004). The online disinhibition effect. Cyberpsychology and Behavior, 7(3), 321-326. http://dx.doi.org/10.1089/1094931041291295. Medline:15257832

Sutton, J. (2005). Healing the hurt within: Understand self-injury and self-harm, and heal the emotional wounds. Oxford: How To Books.

Suzuki, L., \& Calzo, J. (2004). The search for peer advice in cyberspace: An examination of online teen bulletin boards about health and sexuality. Applied Developmental Psychology, 25(6), 685-698. http://dx.doi.org/10.1016/j. appdev.2004.09.002

Tannen, D., \& Wallat, C. (1986). Medical professionals and parents: A linguistic analysis of communication across contexts. Language in Society, 15(3), 295-312. http://dx.doi.org/10.1017/S0047404500011787

Thomas, J., \& Wilson, A. (1996). Methodologies for studying a corpus of doctorpatient interaction. In J. Thomas \& M. Short (Eds.), Using corpora for language research (pp. 92-109). London: Longman.

Watermeyer, J., \& Penn, C. (2009). The organization of pharmacist-patient interactions in an HIV/Aids clinic. Journal of Pragmatics, 41(10), 2053-2071. http://dx.doi.org/10.1016/j.pragma.2009.02.010

Whitlock, J.L., Powers, J.L., \& Eckenrode, J. (2006). The virtual cutting edge: The Internet and adolescent self-injury. Developmental Psychology, 42(3), 407-417. http://dx.doi.org/10.1037/0012-1649.42.3.407. Medline:16756433 
Wiggins, S. (2009). Managing blame in NHS weight management treatment: Psychologizing weight and 'obesity.' Journal of Community and Applied Social Psychology, 19(5), 374-387. http://dx.doi.org/10.1002/casp.1017

Ystgaard, M., Arensman, E., Hawton, K., Madge, N., van Heeringen, K., Hewitt, A., de Wilde, E.J., De Leo, D., \& Fekete, S. (2009). Deliberate self-harm in adolescents: Comparison between those who receive help following self-harm and those who do not. Journal of Adolescence, 32(4), 875-891. http://dx.doi.org/ 10.1016/j.adolescence.2008.10.010. Medline:19028399 